\title{
Analysis of the Residuals between Theoretical Nutations and VLBI Observations
}

\author{
V. Dehant ${ }^{1}$, M. Feissel ${ }^{2,3}$, O. de Viron ${ }^{4}$, M. Yseboodt ${ }^{1}$, and Ch. \\ Bizouard $^{2}$ \\ ${ }^{1}$ Royal Observatory of Belgium ${ }^{2}$ Observatoire de Paris, \\ France ${ }^{3}$ Institut Geographique National, France ${ }^{4}$ Jet Propulsion \\ Laboratory, USA
}

The recent theoretical developments have provided accurate series of nutations, which are close to the Very Long Baseline Interferometry (VLBI) data. At the milliarcsecond (mas) level, three series are available: MHB2000 (Mathews et al. 2000), FG2000 (Getino and Ferrándiz 2000), and SF2000 (Shirai and Fukushima 2000a,b) (see Dehant 2000, and in this volume, for more information and for a short description of these models).

In the first part of our work we have compared these models with the (VLBI) observations (Ma et al. 2000) by computing rms of the residuals for several time intervals of measurements. We have concluded that these series have comparable precision.

In our effort to understand the residual differences between theory and observations, we have investigated the atmospheric effects on annual nutation. All the above nutation models account for a constant atmospheric effect at the prograde annual nutation. The analysis of the atmospheric angular momentum series shows that the amplitude of the atmospheric forced nutation at the prograde annual period is not constant in time. Additionally, there is a contribution to the retrograde annual nutation which can reach $100 \mu$ as (micro arc second) (see Yseboodt et al. 2000). This quite high amplitude is caused by the amplification due to the Free Core Nutation (FCN) resonance at the 432 days period. It must be mentioned that, as shown in Yseboodt et al. (2000), the estimated atmospheric contributions at the different nutation frequencies are dependent on the global circulation model used to derive the atmospheric angular momentum.

In a complementary approach to explain the residuals, we have estimated the contribution of potential errors in the ICRF source positions. Using time series of radio-sources coordinates evaluated for each observation session, we construct a time series of the apparent celestial pole motion resulting from the individual source motions. These motions are then interpreted as spurious nutations, that should be corrected for in the residuals (VLBI observations - theory). We find time variable contributions of this effect to the prograde and retrograde annual nutations at the level of $-20 \mu$ as. We have also estimated contributing errors in the determination of the precession and obliquity rate of respectively $-5 \mu \mathrm{as} /$ year and $-18 \mu \mathrm{as} /$ year. This preliminary test of the contamination of the "apparent pole offset" to nutation may be not negligible and deserves further investigations. 
In summary, the amplitude of the two investigated effects that could influence the observational determination of nutation, namely variable atmospheric excitation and instability of the radiosource coordinates, are consistent with the observed discrepancies between the observations and the theory of nutation.

\section{References}

Dehant, V. 2000, in Proc. of IAU Coll. 180, eds. K. Johnston, D. McCarthy, B. Luzum \& G. Kaplan, Washington, USA, 201

Getino, J. \& Ferrándiz, J.M. 2000, in Proc. of IAU Coll. 180, eds. K. Johnston, D. McCarthy, B. Luzum \& G. Kaplan, Washington, USA, 236

$\mathrm{Ma}, \mathrm{C}$. et al. 2000, Submission to the 1999 IERS Annual Report

Mathews, P.M., Herring, T. \& Buffett, B. 2000, "Modeling of nutation-precession: new nutation series for nonrigid Earth, and insights into the Earth's interior," J. Geophys. Res., submitted

Shirai, T. \& Fukushima, T. 2000a, "Improvement of non-rigid Earth nutation theory by adding a model free core nutation term", Astron. J., submitted, also in Proc. of IAU Coll. 180, eds. K. Johnston, D. McCarthy, B. Luzum \& G. Kaplan, Washington, USA, 223

Shirai, T. \& Fukushima, T. 2000b, "Numerical convolution in the time domain and its apllication to the non-rigid Earth nutation theory", Astron. J., in press

Yseboodt, M., de Viron, O., Chin, T.M. \& Dehant, V., 2000, "Atmospheric excitation of the Earth nutation: Comparison of different atmospheric model", J. Geophys. Res., in preparation. 